\title{
Colonoscopy as a Method of Choice in the Diagnosis of Colorectal Cancer
}

\author{
Sead Buturovic \\ General Hospital, Konjic, Bosnia and Herzegovina \\ Corresponding author: ass. prof. Sead Buturovic, MD, PhD. General hospital, Konjic, Konjic, Bosnia and Herzegovina. E-mail: bolnica_konjic@bih.net.ba
}

\begin{abstract}
Introduction: Epidemiological characteristics of colorectal cancer indicate that in the U.S. colorectal cancer is the second leading cause of death from malignancy, just behind lung cancer. In the 2000 there were approximately 130,200 new cases, of which 56,300 had lethal outcome. In the past 15 years, the incidence and mortality rate has been declining, especially in women. Colorectal cancer is mainly found in people older than 50 years. Carcinoembryonic antigen (CEA) is insufficiently specific for the early detection of the disease. Its normal value is less than $5 \mathrm{~g} / \mathrm{L}$ in the serum. Elevated levels of CEA after surgery indicate a lack of radical surgery, residual neoplasm, hidden distant metastases or recurrent disease. Unfortunately, only $10-15 \%$ of patients with recurrent disease can be successfully re-operated (isolated metastases in the liver or lungs). Colorectal cancer is predominantly adenocarcinoma, the tumor has relatively slow growth. While symptoms occur relatively early, distant metastases have relatively late appearance. Goals: The goals of this study were to remind the fundamental facts about the nature of this disease, to stress the importance of early detection of BC-screening programs, to draw attention to contemporary attitudes in the field of diagnosis and treatment of colorectal cancer, and to show the experience in the treatment of this disease at the Surgical Departments of the General Hospital in Konjic. Results: In the period from 2008-2012 years, at the Surgical Department of the General Hospital in Konjic surgically treated are 34 patients who had colorectal malignancy. There were $21(65 \%)$ male and 13 females (35\%). All patients belonged to the age group of 50-75 years. Only five patients or $15 \%$ prior to admission to the hospital had been diagnosed with a malignant process. All others, or $85 \%$ of the total sample, were admitted to the hospital as emergency cases (erosive gastritis), and after, shorter preparation underwent surgery. Only five (15\%) of patients were admitted electively, already diagnosed with colorectal tumors by colonoscopy. Total number of lethal outcomes at the department was $8(24 \%)$. Three patients died due to cardio-respiratory failure and MOF, and 5 patients due to anastomotic failure and septic shock. Conclusion: In conclusion we can say that in our institution it is necessary to obtain the proper equipment (colonoscope) and educate personnel, so we can introduce colonoscopy as the mandatory screening method of examination, particularly for vulnerable groups.

Key words: Colorectal cancer, colonoscopy, surgical treatment, outcome.
\end{abstract}

\section{INTRODUCTION}

Epidemiological characteristics of colorectal cancer indicate that in the U.S. colorectal cancer is the second leading cause of death from malignancy, just behind lung cancer (1-5). In the 2000 there were approximately 130,200 new cases, of which 56,300 had lethal outcome. In the past 15 years, the incidence and mortality rate has been declining, especially in women. Colorectal cancer is mainly found in people older than 50 years. It is a disease of the developed countries, which is more a reflection of diet and living conditions than racial and ethnic characteristics. Despite all research and advances in this field is still unknown etiology of diseases, and complex and uncertain treatment, require that this problem constantly be followed and studied.

Risk factors for colorectal cancer include diet (animal fats), hereditary syndromes (autosomal-dominant inheritance), colon polyps, non-polyposis syndromes (Lynch syndrome), inflammatory bowel disease, Streptococcus bovis bacteremia, ureterosigmoidostomy and tobacco smoking (1).

Justification for screening program lies in the fact that the early detection and localization of superfi- cial cancers in asymptomatic patients, increases the possibility of surgical cure. The relative risk of disease rises to 1.75 in the cases with close relatives with colorectal cancer and may be higher if the relatives of patients before the age of 60 .

\begin{tabular}{|c|c|c|c|c|}
\hline \multicolumn{3}{|l|}{ Stage } & \multirow{2}{*}{$\begin{array}{l}\text { Pathological } \\
\text { description }\end{array}$} & \multirow{2}{*}{$\begin{array}{l}\text { 5-year } \\
\text { survival }\end{array}$} \\
\hline Dukes & TNM & $\begin{array}{l}\text { Numer- } \\
\text { ical }\end{array}$ & & \\
\hline A & T1NoMo & I & $\begin{array}{l}\text { Ca limited to the } \\
\text { mucosa and sub- } \\
\text { mucosa }\end{array}$ & $>90 \%$ \\
\hline B1 & T2NoMo & I & $\begin{array}{l}\text { Ca extending to } \\
\text { the muscularis }\end{array}$ & $85 \%$ \\
\hline B2 & T3NoMo & II & $\begin{array}{l}\text { Ca extending to } \\
\text { serosa and be- } \\
\text { yond serosa }\end{array}$ & $70-80 \%$ \\
\hline C & TxN1Mo & III & $\begin{array}{l}\text { Ca affects to } \\
\text { regional lymph } \\
\text { nodes }\end{array}$ & $35-65 \%$ \\
\hline $\mathrm{D}$ & TxNxM1 & IV & $\begin{array}{l}\text { Distant metasta- } \\
\text { ses (liver, lungs ...) }\end{array}$ & $5 \%$ \\
\hline
\end{tabular}

Table 1 staging and prognosis of colorectal cancer 
Programs for the early detection of colorectal cancer include digital rectal examination, which should be part of routine systematic examination of adults older than 40 years. Feces for occult blood (Hemoccult test) which is in approximately $50 \%$ of patients with proven colorectal cancer negative Hemoccult test, which is in conjunction with occasional bleeding from the tumor. Colorectal cancer is found only in less than $10 \%$ of the test "positive" cases, and even 20 to $30 \%$ of patients had benign polyps detected. Colorectal neoplasm is found in asymptomatic patients with occult blood in the stool.

Other tests in the diagnosis of colorectal cancer should include sigmoidoscopy, which by the flexible fiber optic sigmoidoscope allows an experienced physician to visualize the colon to $60 \mathrm{~cm}$, which increases cancer detection, because $60-70 \%$ of early lesions are localized in rectosigmoid region, colonoscopy, and possibly irrigography.

Screening techniques for colon cancer in asymptomatic patients are still unsatisfactory. The American Cancer Association proposes an annual digital anal examination after age of 40 , testing stool by $\mathrm{He}-$ moccult test annually from the age of 50, and sigmoidoscopy (preferably flexible) every three to five years for asymptomatic persons who have risk factors for colorectal cancer (2) .

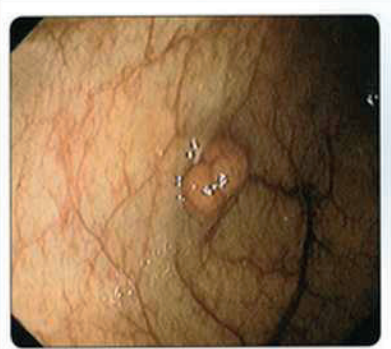

Endoskopisio nalaz polipa rétum

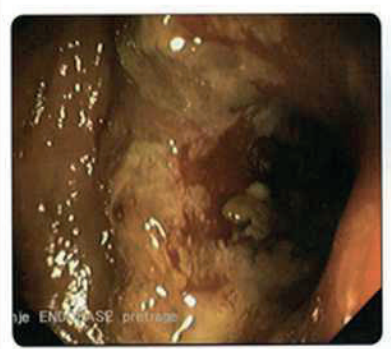

Endoskopsti nslaz karcinoma rektuma

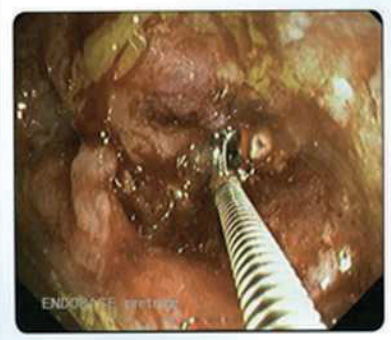

Postupak usimanja biooshles sa barchoma rektuma

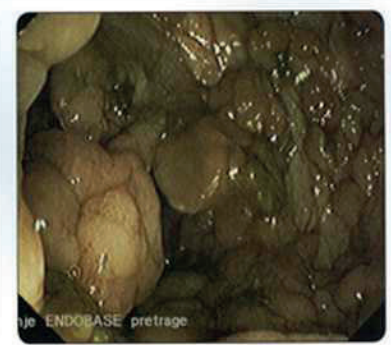

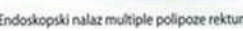

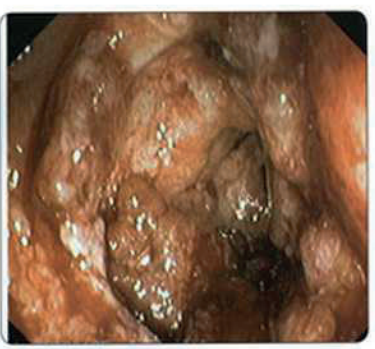

Endoskopskinalaz karcinoma reituma koj

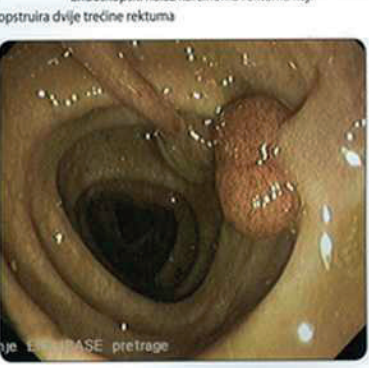

Endoskopsti nalaz polipu a perelyia debelog
Figure 1. Endoscopic findings of colorectal cancer
For people who have risk factors for colorectal cancer, it is necessary to perform every year endoscopy (flexible sigmoidoscopy). Also recommended is total colonoscopy because of possible synchronous tumors (3\% of cancers and $40-50 \%$ of adenomas). Wolf and his associates in 1969 performed firs cecal colonoscopy, and from there begins a new era in gastroenterology. Today, are used the latest video systems that are optimally incorporated in flexible colonoscopy which can examine every part of the colon, the initial part of the ileum, and in every part of it can take a biopsy, or perform therapeutic intervention (24).

Carcinoembryonic antigen (CEA) is insufficiently specific for the early detection of the disease. Its normal value is less than $5 \mathrm{~g} / \mathrm{L}$ in the serum. Elevated levels of CEA after surgery indicate a lack of radical surgery, residual neoplasm, hidden distant metastases or recurrent disease. Unfortunately, only 10-15\% of patients with recurrent disease can be successfully re-operated (isolated metastases in the liver or lungs). Colorectal cancer is predominantly adenocarcinoma, the tumor has relatively slow growth. While symptoms occur relatively early, distant metastases have relatively late appearance.

The most common clinical signs include bleeding from the rectum, chronic anemia, changes in the character of defecation, pain in the abdomen or rectum, and loss of weight. They may also include palpable tumor, slimy stools, occlusion or perforation of the colon that are rare, and distant metastases in the liver, lungs and other organs.

Acute symptomatology include: intestinal obstruction (ileus), which occurs in $7-48 \%$ of patients with colorectal cancer (5). These complications require surgical treatment. Perforation, as a complication of colon cancer with consecutive purulent peritonitis and abdominal abscesses occurs in $0.3-4 \%$ of patients with colon cancer (6). This is especially true in closed gyrus syndrome-a competent ileocecal valve.

\section{GOAL}

The goals of this study were to remind the fundamental facts about the nature of this disease, to stress the importance of early detection of BC-screening programs, to draw attention to contemporary attitudes in the field of diagnosis and treatment of colorectal cancer, and to show the experience in the treatment of this disease at the Surgical Departments of the General Hospital in Konjic.

\section{METHODOLOGY}

For majority of cancers in the colon and rectum radical surgical removal of the tumor is the only potentially curative treatment. Irradiation and chemotherapy have no significance as the primary mode of treatment. Radicular treatment involves surgical removal of the primary tumor resection with a significant part of a healthy tissue (more than $5 \mathrm{~cm}$ from the macroscopic tumor boundaries), and all of the 


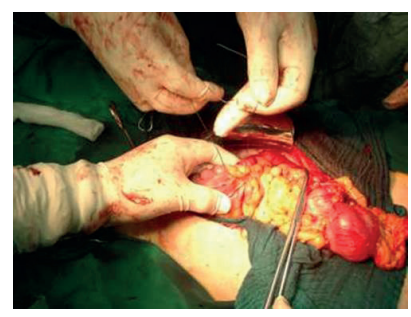

Figure 2. Cole and Turnbull (1960) pointed out the possibih of a large intraluminal spread of malignancy implant
of malignant cells, especially during the surgery and
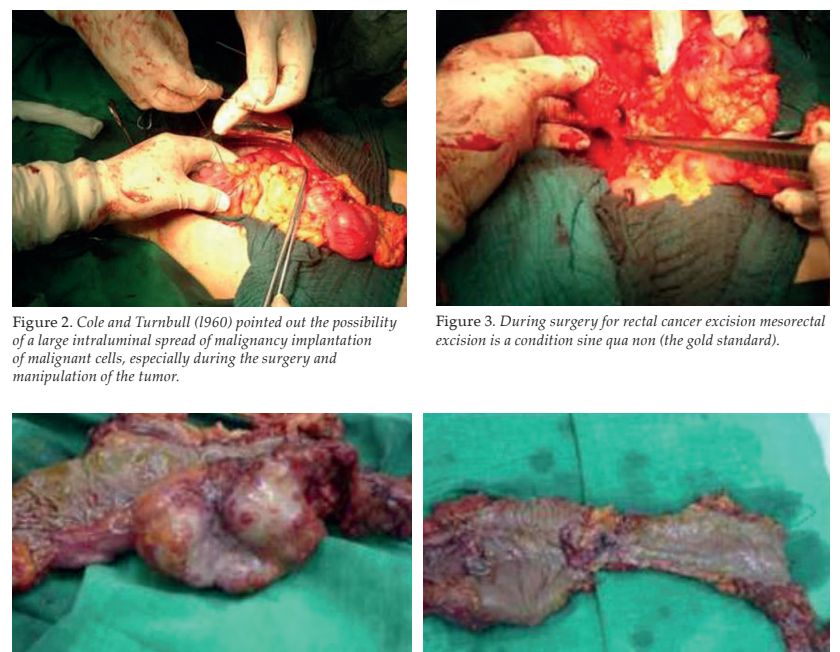

Figure 3. During surgery for rectal cancer excision meso
excision is a condition sine qua non (the gold standard).

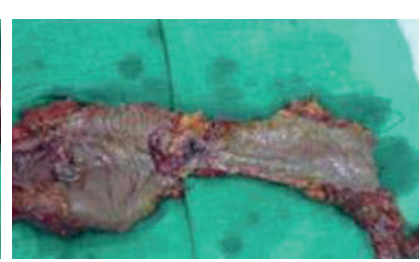

Figure 4. Resected colorectal cancer

lymph glands and vessels that belong to a particular segment of the colon. In case of tumors ingrown into the surrounding structures (abdominal wall, adjacent organ), wide excision in the block can provide effective cure. Individual metastases in one of the liver lobes can be removed by resection. Disseminated metastases in the liver or in the peritoneum are sign of short survival, and in these situations resection of the colon should be avoided (7-9).

Surgical tactics requires early clamping of the colon lumen, above and below the tumor (Cole Turnbull principle), as well as early ligation of the arterial, venous and lymphatic drainage pathways of the corresponding segment of the colon. This significantly reduces the possibility of the dissemination of malignant cells during the operation.

In the past 15 years, laparoscopic surgery, taken over in the diagnosis and therapy of malignant diseases of the colon.

In malignant occlusion of the colon primary anastomosis after emergency resection are very risky, followed by the number of complications and high mortality. This is a result of unprepared colon which is full of stopped faecal masses. Therefore there are much higher concentrations of bacteria, and the wall is damaged distension and edema.

\section{RESULTS}

In the period from 2008-2012 years, at the Surgical Department of the General Hospital in Konjic surgically treated are 34 patients who had colorectal malignancy, which is about $4 \%$ of all surgeries performed within the specified period. There were 21 (65\%) male and 13 females (35\%). All patients belonged to the age group of 50-75 years. Only five patients or $15 \%$ prior to admission to the hospital had been diagnosed with a malignant process. All others, or $85 \%$ of the total sample, were admitted to the hospital as emergency cases (erosive gastritis), and after, shorter preparation underwent surgery. Eight of them (24\%) were operated immediately upon receipt due to an acute abdomen, MOF, with clinical picture of decompen- sated ileus. In the other 21 (62\%) patients, who were admitted to the Department, due to abdominal pain, blood in the stool and interference in the passageileus, after a short diagnostic procedure (laboratory, X-ray, CT scan and echo), was suspected on colorectal malignancy, and all after a short preparation were operated. Only five (15\%) of patients were admitted electively, already diagnosed with colorectal tumors by colonoscopy. Total number of lethal outcomes at the department was 8 (24\%). Three patients died due to cardio-respiratory failure and MOF, and 5 patients due to anastomotic failure and septic shock.

\section{DISCUSSION}

In the area covered by our hospital screening programs are not performed because our hospital lack colonoscopy and our patients contact doctor with severe problems, mainly in a much neglected state.

Because of relatively high percentage of mortality among our patients, we started in the last two years to perform proximal derivation and only loop-ileostomy. From then we did not have more complications and deaths. As a start we initiate the use of laparoscopy in the intraoperative staging of the disease.

\section{CONCLUSION}

In conclusion we can say that in our institution it is necessary to obtain the proper equipment (colonoscope) and educate personnel, so we can introduce colonoscopy as the mandatory screening method of examination, particularly for vulnerable groups.

\section{CONFLICT OF INTEREST: NONE DECLARED.}

\section{REFERENCES}

1. Corman LM.Colon and rectal surgery. B.Lipincott Co.,Philadelphia, 1989.

2. Calne R, Pollard SG. Operative surgery. Gower Medical Publishing, London,1992.

3. Winawer SJ, Fletcher RH, Miller L. et al. Colorectal Cancer: screening, clinical quidelines and rationale. Gastroenterology. 1997; 112(2): 594-642.

4. Atkin W, Cuzick J. Colorectal cancer by onceouly sigmoidoscpi. Lancet. 1993; 341: 736-740.

5. Ahsan H, Neugut Al, Garbowski GC. et al. Family history of colorectal adenomatous polyps and increased risk for colorectal cancer, An Intern Med. 1998; 128(11); 900-905.

6. National Comprehensive Cancer Netwok (NCCN), Colorectal cancer screening, Institute for Clinical Systems. Improvement (ICSI), 2005.

7. Fazio VW, Cherch JM, Delaney CP. Current therapy in colon and rectal surgery, 2nd ed. Philadelphia Elsevier Moshy, 2005: 379-388.

8. Ballinger $\mathrm{AB}$, Anggiansah $\mathrm{C}$. Colorectal cancer: $\mathrm{BMJ}$. 2007; 335: 715-718.

9. Michael F. Primary screening wirh Colonoscopy for colorectal cancer a targeted algorithm? The American Journal od Gastroenterology, 2004; 98(12): 2587-2589. 